\title{
Ablation surgery in patients with persistent atrial fibrillation: An 8-year clinical experience
}

\author{
Stephan Geidel, MD, PhD, ${ }^{a}$ Korff Krause, MD, ${ }^{b}$ Sigrid Boczor, ${ }^{b}$ Karl-Heinz Kuck, MD, PhD, ${ }^{b}$ \\ Michael Lass, MD, PhD, ${ }^{\mathrm{a}}$ Jörg Ostermeyer, MD, PhD, ${ }^{\mathrm{a}}$ and Michael Schmoeckel, MD, PhD ${ }^{\mathrm{a}}$
}

Objective: This analysis was undertaken to evaluate the results of persistent atrial fibrillation ablation procedures concomitant to open surgery and to identify risk factors for persistent atrial fibrillation recurrence.

\begin{abstract}
Methods: Since 2001, a total of 325 consecutive patients with persistent atrial fibrillation (duration, 0.5-33 years) have undergone persistent atrial fibrillation ablation concomitant to open surgery by creating 2 encircling isolation lesions around the left and right pulmonary veins and a connecting lesion between both with the use of radiofrequency ablation procedures. Patients were restudied at discharge, 3 months, and 3 years after surgery.
\end{abstract}

Results: Survivals at the time of reexamination at discharge, 3 months, and 3 years were $97.8 \%, 96.2 \%$, and $94.4 \%$, respectively. Stable sinus rhythm could be documented in $72.1 \%, 73.9 \%$, and $75.6 \%$ of surviving patients, respectively. Long-term persistent atrial fibrillation before surgery and a larger left atrium were predictive of postoperative persistent atrial fibrillation return $(P<.001)$. Statistical analysis demonstrated cutoff points of 5 years for persistent atrial fibrillation and $55 \mathrm{~mm}$ for left atrium diameter; $89.7 \%$ of patients with persistent atrial fibrillation duration of less than 5 years and $84.5 \%$ of patients with left atrium size of $55 \mathrm{~mm}$ or less were in stable sinus rhythm at late follow-up. Cardiac rhythm at discharge and at 3 months was predictive of long-term rhythm prognosis $(P<.001)$. Age, gender, concomitant diseases (eg, arterial hypertension, diabetes, renal insufficiency, or pulmonary disease), and the underlying cause of heart disease did not significantly influence the postoperative cardiac rhythm.

Conclusions: The duration of persistent atrial fibrillation and the size of the left atrium are the most reliable preoperative variables to predict the success rate of ablation concomitant to open surgery. The probability of reestablishing stable sinus rhythm is excellent when persistent atrial fibrillation duration is short and left atrium size is small. (J Thorac Cardiovasc Surg 2011;141:377-82)

Atrial fibrillation (AF) is the most prevalent cardiac arrhythmia treated in clinical practice. In cardiac surgery, persistent atrial fibrillation (pAF) is exceptionally important because it is frequently found as a concomitant disease in patients who are scheduled for open surgery for other reasons. ${ }^{1}$ The morbidity associated with pAF results in significantly poorer survival than in patients with stable sinus rhythm (SR). ${ }^{2}$ Since the Cox maze procedure demonstrated that AF can be eradicated, less-invasive ablation procedures were brought to clinical practice a decade ago. ${ }^{3-5}$ The present study evaluates the early and late results of a strategy that was started in 2001 using radiofrequency (RF) ablation in patients with concomitant pAF who were scheduled for open surgery and identifies the risk factors for postoperative $\mathrm{pAF}$ recurrence. The data of 8 years of clinical experience with 325 cases were analyzed.

\footnotetext{
From the Abteilungen für Herzchirurgie ${ }^{\mathrm{a}}$ und Kardiologie, ${ }^{\mathrm{b}}$ Asklepios Klinik St Georg, Hamburg, Germany.

Disclosures: Authors have nothing to disclose with regard to commercial support. Received for publication Dec 9, 2009; revisions received Feb 21, 2010; accepted for publication March 21, 2010; available ahead of print April 29, 2010.

Address for reprints: Stephan Geidel, MD, PhD, Abteilung für Herzchirurgie, Asklepios Klinik St Georg, Lohmühlenstraße 5, 20099 Hamburg, Deutschland (E-mail: s.geidel@asklepios.com; StGeidel@aol.com).

$0022-5223 / \$ 36.00$

Copyright $(c) 2011$ by The American Association for Thoracic Surgery doi:10.1016/j.jtcvs.2010.03.024
}

\section{PATIENTS AND METHODS}

The investigation comprised 325 consecutive patients with a given indication for open surgery and concomitant persistent, not paroxysmal, AF (following the terminology of the current American College of Cardiology/ American Heart Association/European Society of Cardiology guidelines ${ }^{6}$ ). This analysis included only patients who had persistent, not paroxysmal, $\mathrm{AF}$ for at least 0.5 years (median: 4.0 years, Perc25/75 1.5/8.0; range: 0.5-33 years) and were scheduled for surgery at the Asklepios Klinik St Georg between February 2001 and January 2009. The patient characteristics are shown in Table 1. Exclusion criteria for concomitant ablation in other cases with pAF $(n=60)$, as defined in 2001 , were pAF duration of less than 0.5 years, emergency operation, severely reduced left ventricular ejection fraction $(<15 \%)$, acute endocarditis or myocardial infarction $(<7$ days), considerable cachexia (body mass index $\leq 18$ ), and severe intracardiac thrombosis or extreme left atrium (LA) size (diameter $\geq 72 \mathrm{~mm}$ ).

\section{Surgical Technique}

The ablation procedure included a bilateral isolation of the right pulmonary veins (RPVs) and left pulmonary veins (LPVs), which were connected in the middle by a transverse lesion across the posterior LA wall. When the LA had to be opened (eg, during mitral valve [MV] surgery), the Cobra device (Boston Scientific Corp, San Jose, Calif) was used for RF ablation (100 W RF power for 120 seconds); the local temperature was set at $70^{\circ} \mathrm{C}$ (monopolar endocardial application). For this procedure, the LA was opened via a standard left atriotomy and MV analysis was performed. Next, by performing a left atriotomy, the first ablation lesion completed the isolation of the RPVs from the inferior to the superior RPV (Figure 1). Isolation of the LPVs was performed with a semicircular ablation line close to the inferior LPV and another one around the superior LPV. These were 


$$
\begin{aligned}
& \text { Abbreviations and Acronyms } \\
& \begin{aligned}
\text { AF } & =\text { atrial fibrillation } \\
\text { CABG } & =\text { coronary artery bypass grafting } \\
\text { DC } & =\text { direct current } \\
\text { ECG } & =\text { electrocardiogram } \\
\text { LA } & =\text { left atrium } \\
\text { LPV } & =\text { left pulmonary vein } \\
\text { MV } & =\text { mitral valve } \\
\text { NYHA } & =\text { New York Heart Association } \\
\text { OR } & =\text { odds ratio } \\
\text { pAF } & =\text { persistent atrial fibrillation } \\
\text { RF } & =\text { radiofrequency } \\
\text { RPV } & =\text { right pulmonary vein } \\
\text { SR } & =\text { sinus rhythm }
\end{aligned}
\end{aligned}
$$

connected by a transverse lesion. Arrangements to avoid thermic esophageal injury were as follows: The ablation was performed under direct view during conventional open surgery only, the transesophageal echocardiogram probe was removed during the ablation procedure, a dry compress was passed behind the LA before energy delivery, the flexible ablation probe was adapted to the tissue without pressure, the local temperature was set at only $70^{\circ} \mathrm{C}$, and cachectic patients were excluded.

In cases without a left atriotomy (eg, aortic valve procedures or coronary artery bypass grafting [CABG]), the Atricure device (Atricure Inc, Cincinnati, Ohio) was used for bipolar RF ablation: Isolation of the RPVs and LPVs was performed on cardiopulmonary bypass with the heart beating by impacting the atrial tissue between the jaws of the Atricure hand piece and delivering energy with a local temperature of $40^{\circ} \mathrm{C}$ to $55^{\circ} \mathrm{C}$. Ablation was terminated when the ablation and sensing unit indicated that the tissue conductance was at least 10 seconds less than 2.5 millisiemens, which is in parallel with transmurality of the lesion. Next, a purse-string 2-0 Ethibond suture (Ethicon, Johnson \& Johnson Inc, New Brunswick, NJ) was set at the posterior LA wall. The distal jaw was inserted through an incision in the direction of the LPVs, and ablation was performed after clamp closure. The distal jaw was inserted in the direction of the RPVs, and the connecting lesion was completed (Figure 1). The purse-string suture was closed and protected with a 3-0 Prolene (Ethicon) suture. The LA appendage was occluded routinely from the endocardial side (MV cases; using two 3-0 Prolene running sutures) or the epicardial side (non-MV cases; using 4-0 Prolene [Ethicon] sutures; double layer) in cases with an LA diameter of more than $55 \mathrm{~mm}$.

\section{Management of Cardiac Rhythm and Follow-up}

Transthoracic echocardiogram and standard 12-lead electrocardiogram (ECG) were performed on admission and before discharge by an experienced cardiologist. LA size was assessed by evaluating the LA diameter (anteroposterior diameter on parasternal axis view at end systole). An LA of more than $55 \mathrm{~mm}$ was termed as large ( $\leq 55 \mathrm{~mm}$, small). A tricuspid regurgitation of grade 2 or more documented by transthoracic echocardiogram was interpreted as an indication to perform concomitant tricuspid valve repair. Amiodarone administration was started with an intravenous bolus of $300 \mathrm{mg}$ before the end of cardiopulmonary bypass, followed by an infusion of $900 \mathrm{mg} / \mathrm{d}$ for 3 days. Oral administration of $5 \times 200 \mathrm{mg}$ up to 7 to $10 \mathrm{~g}$ depending on body weight was begun, followed by $1 \times 200 \mathrm{mg} / \mathrm{d}$ for 3 months. In cases of thyroid disease, amiodarone incompatibility, or other contraindication for amiodarone administration, sotalol was given alternatively (an intravenous bolus of $10 \mathrm{mg}$ and then $1 \mathrm{mg} / \mathrm{kg}$ for 24 hours; oral administration of $2-3 \times 40-80 \mathrm{mg}$ for 3 months). When postoperative bradycardia persisted for more than 10 days, the amiodarone/sotalol therapy was stopped. An indication for permanent pacemaker implantation was bradycardia persisting for 14 days. In cases with early $\mathrm{AF}$ recurrence during hospital stay after saturation with amiodarone/sotalol and after exclusion of intracardiac thrombosis by transesophageal echocardiogram, direct current (DC) cardioversion was recommended. During initial antiarrhythmic drug saturation, patients were observed for at least 7 days with continuous monitoring (first in the intensive care unit and then in an intermediate care unit). Heparin was given after resolution of postoperative bleeding. Patients with heart valve repair or bioprosthesis received coumarin for 3 months. Patients with mechanical valves, lifelong anticoagulation, or CABG received aspirin for lifetime. All survivors were restudied before discharge $(n=318$; $10 \pm 2$ days); 307 patients were studied early ( $3 \pm 1$ months) and 287 patients were studied late ( $3.0 \pm 1.6$ years) after surgery by standard 12-lead ECG and clinical examination. A standard 24-hour ECG registry also was performed at early and late follow-ups. According to the protocol during the hospital stay, the following variables and events were documented: age, gender, pAF duration, LA size, left ventricular ejection fraction, cause of heart disease, concomitant pulmonary disease, diabetes, arterial hypertension, renal insufficiency, New York Heart Association (NYHA) class, aortic crossclamping time, cardiopulmonary bypass time, total operation time, ablation time, total ablation procedure time, postoperative drug therapy, permanent pacemaker implantation, early AF recurrence, DC cardioversion (successful, unsuccessful), cardiac and noncardiac death, reoperation for bleeding, perioperative myocardial infarction, cerebrovascular events, pneumonia, and wound infection. At follow-up, the following variables and events were noted: cardiac and noncardiac death, cardiac rhythm, reoperation for recurrent heart disease, endocarditis, myocardial infarction, stroke, anticoagulation, and NYHA class.

\section{Statistical Analysis}

Quantitative preoperative and operative data were described by arithmetic mean \pm standard deviation or (if appropriate) by median and Perc25/75. Qualitative distributed data were presented as absolute frequencies. For data assessment, an explorative data analysis was performed; no adjustments for multiple tests were calculated. Univariate and multivariate binary logistic regression models were used to evaluate pAF recurrence and persistence early and late after surgery. Continuous measurements and parameters grouped by clinical relevant values (eg, LA size $\geq 55 \mathrm{~mm}$ vs $<55 \mathrm{~mm}$; pAF duration $\geq 5$ years vs $<5$ years) were included. Qualitative characteristics were also compared using chi-square tests (Fisher's exact test and McNemar test). Changes in NYHA class were investigated using the Friedman test (Monte Carlo method; upper bound of $99 \%$ confidence given). All $P$ values were 2 tailed and interpreted as nominal. Analysis was performed with the Statistical Package for the Social Sciences for Windows 11.5.2.1 (SPSS Inc, Chicago, Ill), which uses the label " $\operatorname{Exp}(B)$ )" for the odds ratio $(\mathrm{OR})$, showing the OR of the independent with the dependent variable and the predicted change in odds for a unit increase in the corresponding independent variable $(\mathrm{ORs}<1$ correspond to decreases; ORs $>1.0$ correspond to increases in odds; ORs $\sim 1.0$ indicate that unit changes in that independent variable do not affect the dependent variable).

\section{RESULTS}

Of 325 cases in 201 patients, ablation was performed concomitant to MV surgery $(61.8 \%)$. In 124 patients, other procedures (eg, aortic valve replacement or CABG; $38.2 \%$ ) were carried out. All relevant surgery data are shown in Table 2. Hospital mortality was $2.2 \%$ ( 3 noncardiac and 4 cardiac deaths; $3 / 7$ patients died in SR, 4/7 patients had $\mathrm{AF})$. One patient $(0.3 \%)$ underwent reoperation for bleeding, 2 patients $(0.6 \%)$ had perioperative myocardial infarction, 17 patients $(5.2 \%)$ had cerebrovascular events 
TABLE 1. Characteristics of 325 patients with concomitant persistent atrial fibrillation

\begin{tabular}{ll}
\hline Age, y & $70 \pm 9(36-92)$ \\
Gender, male/female & $196 / 129(60.3 \% / 39.7 \%)$ \\
euroSCORE & $7.0 \pm 2.3(2-12)$ \\
NYHA class & $3.1 \pm 0.4(2-4)$ \\
LVEF, \% & $53 \pm 13(15-88)$ \\
pAF duration, y & $5.8 \pm 6.0(0.5-33 ;$ median: \\
& $4.01 .5 / 8 ; \mathrm{IQR}: 6.0)$ \\
LA diameter,* mm & $53 \pm 7(36-71)$ \\
Severe MV disease & $201(61.8 \%)$ \\
Significant CAD & $116(35.7 \%)$ \\
Relevant TR (grade $\geq 2)$ & $91(28.0 \%)$ \\
Severe AV disease & $66(20.3 \%)$ \\
Anticoagulation (coumarin) & $214(65.8 \%)$ \\
History of failed interventional & $16(4.9 \%)$ \\
$\quad$ AF ablation & $110(33.8 \%)$ \\
Failed DC cardioversion + antiarrhythmic & \\
$\quad$ med. & \\
\hline
\end{tabular}

$A F$, Atrial fibrillation; $A V$, aortic valve; $C A D$, coronary artery disease; $L A$, left atrium; $L V E F$, left ventricular ejection fraction; $M V$, mitral valve; $N Y H A$, New York Heart Association; $p A F$, persistent atrial fibrillation; $T V$, tricuspid valve; $I Q R$, interquartile range. The euroSCORE is an established score to evaluate the predicted risk of cardiac operations (low risk: 1-2 points; moderate risk: $3-5$ points; high risk: $\geq 6$ points). *The LA diameter at discharge ( $10 \pm 2$ days after surgery) was $49 \pm 6 \mathrm{~mm}$. MV cases (endocardial ablation) had significantly larger LA diameters $(56.5 \pm 6.2 \mathrm{~mm})$ but shorter duration of pAF (5.6 \pm 6.0 years; median, 4.0$)$ than non-MV cases (bipolar ablation, LA diameter: $48.6 \pm 4.7 \mathrm{~mm}$; pAF duration: $6.0 \pm 6.1$ years; median, 4.0 years; $P<.001$ and $P=.095$, respectively). Patients with isolated CABG had an LA size of $47.9 \pm 4.4 \mathrm{~mm}$ and a pAF duration of $6.9 \pm 7.0$ years (median, 5.0 years). AV cases and an LA size of $48.8 \pm 4.5 \mathrm{~mm}$ and a pAF duration of $50.3 \pm 44$ years (median, 3 years).

$(\mathrm{n}=10[2.7 \%]$ with only transient ischemic attack; $\mathrm{n}=7$ [1.9\%] with stroke, including 2 cases of cerebral hemorrhage; the others had ischemia), 10 patients $(3.1 \%)$ had pneumonia, and 7 patients $(2.2 \%)$ had wound infection. A total of 285 patients $(87.7 \%)$ received amiodarone, and 40 patients $(12.3 \%)$ received sotalol. During the hospital stay, 99 of 153 patients $(64.7 \%)$ with early AF recurrence (47.1\% of all) had DC cardioversion ( $\mathrm{n}=50$ were successful, $50.5 \%$ ), and 10 patients converted to SR spontaneously. Fifteen patients had a pacemaker implanted because of persisting bradycardia $(4.6 \%)$. A short episode of postoperative self-terminating atrial flutter was observed in 1 patient. Ten days postoperatively, 229 of 318 patients $(72.1 \%)$ were discharged in regular SR.

Survival was $96.2 \%$ at 3 months and $94.4 \%$ at 3 years follow-up (8 cardiac and 9 noncardiac deaths). The mean survival time was 80 months (75/83 months; $95 \%$ confidence interval). Three patients underwent reoperation for recurrent heart disease, 3 patients had endocarditis, 2 patients had myocardial infarction, and 4 patients with $\mathrm{AF}$ recurrence had stroke ( $\mathrm{n}=2$ with ischemia after thromboembolism, $\mathrm{n}=2$ with hemorrhage). At 3 months, the conversion rate to stable SR with freedom of $\mathrm{AF}$ or atrial flutter was $73.9 \%$. At 3 years, $75.6 \%$ of patients had stable SR (between early and late follow-up, 2 survivors had AF recur-

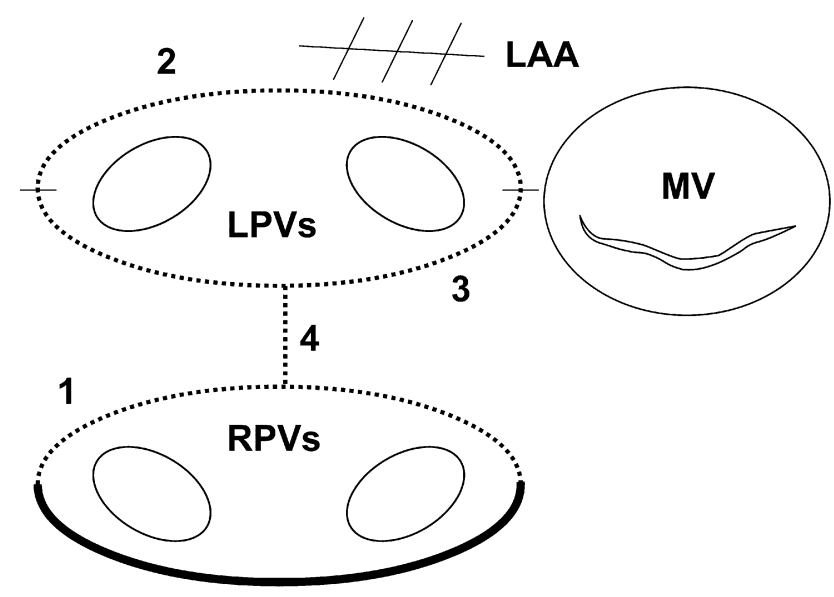

monopolar RF ablation lesions (1-4) surgical incision

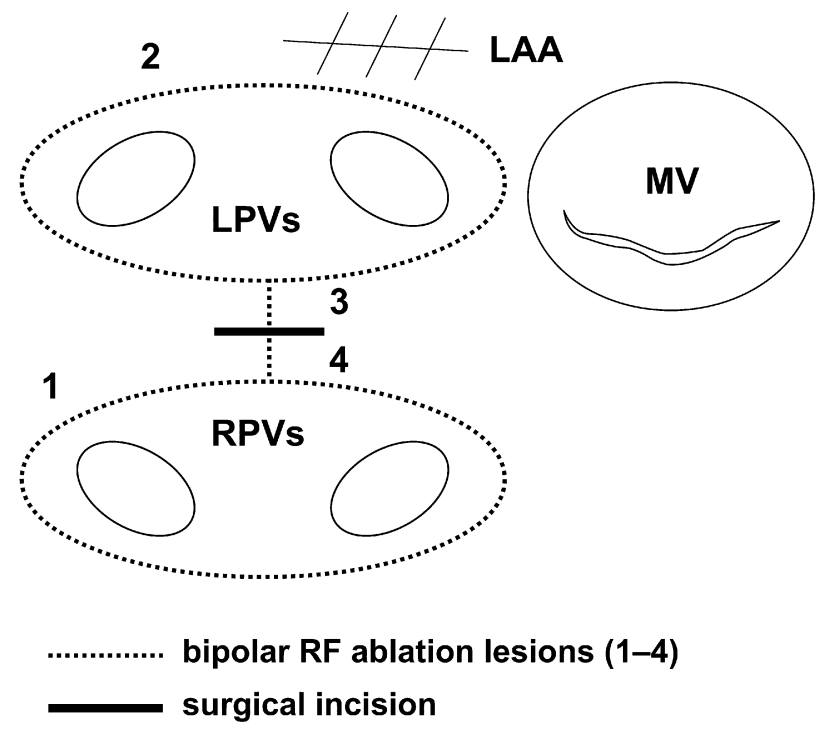

FIGURE 1. Lesion pattern of ablation, which was normally performed in 1 to 4 steps: isolation of RPVs and LPVs plus a connecting lesion on the posterior LA wall using monopolar endocardial RF ablation during MV surgery (top) or bipolar RF ablation in non-MV cases (bottom). The LA appendage was sutured routinely from the endocardial side (MV cases) or epicardially (non-MV cases) in patients with an LA diameter more than $55 \mathrm{~mm}$. LAA, Left atrial appendage; $L P V$, left pulmonary vein; $R P V$, right pulmonary vein; $M V$, mitral valve; $R F$, radiofrequency.

rence and persistence and 6 patients spontaneously converted to stable SR). At 3 years, $73.4 \%$ of mitral cases (monopolar approach) were in SR and $78.8 \%$ of nonmitral cases (bipolar approach) were in SR (isolated CABG: $78.3 \%$; isolated aortic valve: $81.8 \%$ ). At 5 years, 49 of 69 survivors $(71.0 \%)$ were in SR.

With univariate logistic regression analysis, the variables preoperative pAF duration and preoperative LA size were predictive of cardiac rhythm late after surgery $(P<.001$ 
TABLE 2. Surgical data of 325 patients with concomitant persistent atrial fibrillation ablation

\begin{tabular}{ll}
\hline Procedures: AV surgery (isolated) & 44 \\
AV surgery (combined with other surgery) & 16 \\
CABG (isolated) & 59 \\
CABG (combined with other surgery) & 5 \\
MV surgery & 78 \\
MV surgery (combined with other surgery) & 123 \\
Operation time, min & $188 \pm 25$ \\
CPB time, min & $119 \pm 27$ \\
Aortic crossclamping time, min & $78 \pm 30$ \\
Intermittent crossclamping (CABG + ablation) & 60 \\
Cardioplegia (Bretschneider solution) & 265 \\
Ablation time, min & $6.0 \pm 2.1$ \\
Total ablation procedure time, min & $11.8 \pm 2.5$ \\
\hline$A S D$, Atrial septal defect; $A V$, aortic valve; $C A B G$, coronary artery bypass grafting; \\
$C P B$, cardiopulmonary bypass; $C A B G$, coronary artery bypass grafting; $M V$, mitral \\
valve. Repair was performed in $75.1 \%$ of MV cases, and replacement was performed \\
in $24.9 \%$ of MV cases.
\end{tabular}

and $P<.001$, respectively). A long duration of $\mathrm{AF}$ at the time of surgery was detected as an incremental risk factor for $\mathrm{AF}$ return after ablation $(P=.001$, at the time of discharge for grouped parameters and continuous measurement; $P<.0001$ at 3 months and 3 years follow-up). Larger LA size was found as another risk factor (for grouped parameters and continuous measurement at 3 months and 3 years follow-up; $P=.0002$ and $P=.0003$, respectively). Statistical data analysis demonstrated cutoff points of 5 years for $\mathrm{pAF}$ duration and $55 \mathrm{~mm}$ for LA diameter;
$89.7 \%$ of patients $(148 / 165)$ with pAF duration of less than 5 years and $84.5 \%$ of patients $(164 / 194)$ with LA size of $55 \mathrm{~mm}$ or less were in stable SR at late follow-up. Moreover, cardiac rhythm at 3 months follow-up was predictive of long-term rhythm prognosis $(P<.001)$. With multivariate binary logistic regression analysis, the best prediction of long-term rhythm prognosis could be shown for the variable cardiac rhythm at 3 months after surgery $(P<.0001)$. Gender, preoperative left ventricular ejection fraction, associated coronary artery or tricuspid valve disease, the underlying cause of MV disease, concomitant diseases (eg, arterial hypertension, diabetes, renal insufficiency, or pulmonary disease), and age did not significantly influence the postoperative cardiac rhythm (Table 3). At late follow-up, 200 of 287 patients $(69.7 \%)$ did not require anticoagulation (all 69 patients with $\mathrm{AF}$ and 17 patients with postoperative SR still received anticoagulation). At 3 months, all patients were taking antiarrhythmic drugs. At 3 years, only 62 patients $(21.6 \%)$ were not taking any antiarrhythmic drugs, and 225 patients $(78.4 \%$ ) were still taking medication, normally a $\beta$-blocker.

Functional class improved significantly after surgery (decrease from NYHA $3.1 \pm 0.4$ to $1.7 \pm 0.5 ; P<.0001)$, particularly when stable SR was achieved $(1.5 \pm 0.6$ [SR] vs $2.1 \pm 0.6[\mathrm{pAF}])$, with $52 \%$ of patients $(114 / 218)$ in NYHA I and $41 \%$ of patients (90/218) in NYHA II in the SR group, and only $12 \%$ of patients $(8 / 69)$ in NYHA I and $68 \%$ of patients $(47 / 69)$ in NYHA II in the group with AF recurrence $(P=.038)$.

TABLE 3. Risk factor analysis for persistent atrial fibrillation recurrence after ablation surgery (3 follow-up times)

\begin{tabular}{|c|c|c|c|}
\hline Risk factor & 10 d $(n=318)$ & $3 \mathrm{mo}(\mathrm{n}=307)$ & $3 y\left(n=287^{*}\right)$ \\
\hline & $P$ value and $\operatorname{Exp}(B)$ & $P$ value and $\operatorname{Exp}(B)$ & $P$ value and $\operatorname{Exp}(B)$ \\
\hline pAF duration, mo & .001 and 1.072 & .000003 and 1.114 & .000002 and 1.124 \\
\hline $\mathrm{pAF}$ duration $\geq 5 \mathrm{y} \dagger$ & .001 and 2.333 & .000001 and 4.357 & .0000001 and 7.251 \\
\hline LA size, $\mathrm{mm}$ & .561 and 1.011 & .0002 and 1.080 & .0003 and 1.100 \\
\hline LA size $>55 \mathrm{~mm} \dagger$ & .318 and 1.308 & .0003 and 2.846 & .0002 and 3.730 \\
\hline Age, y & .164 and 1.022 & .431 and 1.013 & .277 and 1.019 \\
\hline Age $\geq 70 y$ & .236 and 1.365 & .251 and 1.385 & .235 and 1.425 \\
\hline Gender (male) & .405 and 0.805 & .537 and 0.841 & .056 and 0.568 \\
\hline NYHA class, grade & .289 and 0.709 & .984 and 1.007 & .574 and 1.226 \\
\hline LVEF, \% & .074 and 1.018 & .225 and 1.013 & .164 and 1.016 \\
\hline Relevant MV disease & .229 and 0.731 & .894 and 0.963 & .326 and 1.344 \\
\hline Relevant AV disease & .436 and 0.778 & .541 and 0.808 & .416 and 0.737 \\
\hline TV disease $\geq$ grade & 2.712 and 0.896 & .782 and 1.090 & .443 and 1.291 \\
\hline Significant CAD & .057 and 1.648 & .866 and 1.049 & .351 and 0.752 \\
\hline Bipolar ablation & .097 and 1.443 & .967 and 1.019 & .198 and 1.154 \\
\hline Pulmonary disease & .308 and 1.383 & .282 and 1.436 & .462 and 1.310 \\
\hline Arterial hypertension & .880 and 1.040 & .547 and 1.184 & .350 and 1.322 \\
\hline Diabetes mellitus & .454 and 0.781 & .903 and 1.043 & .943 and 1.027 \\
\hline Renal insufficiency & .751 and 0.887 & .633 and 0.817 & .542 and 1.297 \\
\hline
\end{tabular}

$\overline{A V}$, Aortic valve; $C A D$, coronary artery disease; $L V E F$, left ventricular ejection fraction; $M V$, mitral valve; $N Y H A$, New York Heart Association; $T V$, tricuspid valve. $* \mathrm{n}=22$ still missing. $\dagger$ Cutoff points in the receiver operating characteristic analysis: Cardiac rhythm at 3 months was predictive of rhythm at late follow-up $(P<.0001)$. The Exp(B) column is the SPSS's label for the OR, showing the OR of the independent with the dependent variable and the predicted change in odds for a unit increase in the corresponding independent variable (ORs $<1$ correspond to decreases; ORs $>1.0$ correspond to increases in odds; ORs $\sim 1.0$ indicate that unit changes in that independent variable do not affect the dependent variable). 


\section{DISCUSSION}

Other research has demonstrated that AF initiation originates from foci predominantly located in the LA pulmonary vein junctional area and that $A F$ is maintained by activation wave fronts of reentrant circuits. ${ }^{7-10}$ Therefore, surgeons initially tried to follow the principles of the maze procedure for AF ablation surgery (combination of PV isolation and "complex" atrial lesions/incisions to block reentrant circuits), ${ }^{3-5}$ even if this concept was invasive and complicated. Because it was anticipated that the mechanisms of AF initiation and maintenance vary and are related with individual electrophysiologic/structural changes (particularly when AF has become persistent or permanent), ${ }^{6,11-13}$ the configuration of the lesion pattern became a relevant topic. When we began performing AF ablation surgery in 2001, we tried to simplify the ablation concept of complex left and right atrial lesions, as reported by others in $2000,{ }^{4,5}$ with the intention of reducing the number of lesions to what we thought was an absolutely necessary minimum (PV isolation and an additional connecting lesion). Nevertheless, postoperative atrial flutter (what is expected to occur in some cases when, eg, a mitral isthmus lesion is omitted) was found in only 1 of 325 patients (which is an argument against the necessity of this lesion and the reason why we did not use more lesions later). Instead, our data are in line with the experience of other groups that investigated AF ablation concepts during open surgery: A block of AF wavelets sustained by foci predominantly located inside the pulmonary veins and additional rhythm protection, including medical therapy, results in SR during a period of approximately 6 months after surgery in the majority of patients. ${ }^{14-16}$ However, reliable long-term data of pAF ablation surgery are scarce in the literature, and the long-term effects on cardiac rhythm and survival are still unknown.

RF energy has become the most widely used energy source for AF ablation surgery. Khargi and colleagues ${ }^{17}$ described an SR conversion rate of $79 \%$ at 12 months in 63 non-MV cases and concomitant monopolar endocardial $\mathrm{RF}$ ablation. Other research has demonstrated direct surgical advantages of bipolar RF ablation compared with a monopolar endocardial approach in non-MV cases because of significantly shorter ablation times (because the atrial tissue can be impacted during ablation) and total ablation procedure times (because standard left atriotomy does not have to be performed). ${ }^{18}$ Further, a possible deficiency of monopolar endocardial surgery is that transmurality cannot be "guaranteed,' and rare but fatal complications can occur as the result of deep lesions. ${ }^{19}$ However, with some simple arrangements to avoid thermic esophageal injury, the risk for this fatal complication is low and did not occur in our series of more than $200 \mathrm{MV}$ cases. The advantage of an endocardial monopolar application during MV surgery is that the LA is already open, and the lesions can be set under direct view on the atrial tissues. Nevertheless, the surgical advantages of the bipolar RF approach in non-MV cases convinced us to apply the bipolar concept to our standard procedure to treat permanent $\mathrm{AF}$ during $\mathrm{CABG}$ or aortic valve surgery. ${ }^{18}$ The concepts of monopolar endocardial and bipolar RF ablation surgery are both useful and reliable and should be performed according to the surgeon's practice and experience.

Our data demonstrate that among patients undergoing open surgery with pAF, apart from the LA size, the preoperative AF duration particularly influences the ability of establishing stable SR. These findings confirm the 2006 data of Melo and colleagues ${ }^{20}$ from an international registry, who stated that the LA size is " the best predictor of (ablation) success" in a heterogeneous group of patients with MV disease and different forms of $\mathrm{AF}$, and our earlier research data published in $2005 .{ }^{21}$ In 2008, Beukema and colleagues ${ }^{22}$ reported a conversion rate to stable SR at 5 years follow-up in $55 \%$ of 285 patients with $\mathrm{AF}$ ablation and predominately MV disease. The predictors of AF recurrence in that study were also the duration of AF and LA size. In 2005, Gaynor and colleagues ${ }^{23}$ reported that the most significant predictor of late AF recurrence after Cox maze surgery was the duration of preoperative AF. However, it must be anticipated that the variable predictor for $\mathrm{AF}$ surgery failure as an independent risk factor is probably not the LA size or AF duration itself, but the cellular morphologic/electrophysiologic changes ("damage" = atrial remodeling) correlated with progressive LA enlargement or long-time AF duration. Our thesis is that these factors are of significant relevance for the success of AF ablation surgery. Normally, the decision to perform concomitant pAF ablation during open surgery depends mainly on a risk/benefit assessment of the procedure and the ambition of the individual patient. Our data may help to assess whether concomitant ablation surgery can be performed with success in an individual patient. The described inclusion/exclusion criteria for ablation are still followed at Asklepios Klinik St Georg. However, if a patient has a high risk for ablation surgery failure, we are now more reticent and sometimes refrain from ablation, particularly when the clinical situation is complex. In patients with good preconditions (small LA size, short pAF duration, predicted success rate [stable SR] of $\sim 90 \%$ ), concomitant ablation surgery is recommended. We interpret the good long-term results in our non-MV cases (CABG: $78.3 \% \mathrm{SR}$, aortic valve surgery: $81.8 \% \mathrm{SR}$ ) as a consequence of the small LA size and the relatively short period of $\mathrm{AF}$, particularly in aortic valve cases. However, in patients with presumptively advanced electrical/structural changes, it would be of interest to identify highly damaged/diseased atrial myocardium outside the pulmonary vein and LA junctional area perhaps on the basis of histologic analysis and fibrillation electrograms, 
and with this information selectively ablate or isolate all structures potentially responsible for arrhythmia.

\section{Study Limitations}

The study was not designed for patients with paroxysmal AF or pAF persisting for less than 0.5 years (which was our cutoff set in 2001), and there was no follow-up at exactly 6 months. This limits the comparability with other studies using other inclusion/exclusion criteria and different follow-up times. Our data represent only a single-center experience. The study consists of a heterogeneous group of patients regarding the type of cardiac pathology, which may have influenced the results. The data were not evaluated under randomized conditions. Two different ablation devices were used. The transmurality of the ablation lesions was not investigated in the individual patient. For rhythm evaluation at early and late follow-ups, only 12-lead-ECG, clinical examination, and standard 24-hour ECG registries were used, but no 7-day Holter monitoring or implantable ECG loop recorders were used, which have been shown to improve the completeness of follow-up data in other studies. ${ }^{24,25}$ The late follow-up did not include an echocardiographic investigation of LA function, which also limits the completeness of the data. Postoperative anticoagulation management was not dependent on the size and contractility of the atria.

\section{CONCLUSIONS}

The data allow the evaluation of the results of an RF ablation strategy concomitant to open surgery in patients with pAF duration of 0.5 to 33 years. Regular SR can be achieved in the majority of patients, and this remains stable over time. The SR conversion rate is approximately $90 \%$ in cases with "good preconditions" (ie, small LA size and short pAF duration). Preoperative LA size and pAF duration were identified as useful variables in predicting the success rate of ablation surgery. Preoperative long-term pAF and larger LA size are risk factors for pAF ablation surgery failure in patients undergoing open surgery. The status of cardiac rhythm 3 months after surgery is predictive of longterm rhythm prognosis.

\section{References}

1. Brodell GK, Cosgrove D, Schiavone W, Underwood DA, Loop FD. Cardiac rhythm and conduction disturbances in patients undergoing mitral valve surgery. Cleve Clin J Med. 1991;58:397-9.

2. Benjamin EJ, Wolf PA, D'Agostino RB, Silbershatz H, Kannel WB, Levy D. Impact of atrial fibrillation on the risk of death: the Framingham Heart Study. Circulation. 1998;98:946-52.

3. Cox JL, Schuessler RB, Lappas DG, Boineau JP. An $8 \frac{1}{2}$ year clinical experience with surgery for atrial fibrillation. Ann Thorac Surg. 1996;224:267-75.

4. Melo J, Andragao P, Neves J, Ferreira M, Timoteo A, Santiago T, et al. Endocardial and epicardial radiofrequency ablation in the treatment of atrial fibrillation with a new intraoperative device. Eur J Cardiothorac Surg. 2000;18:182-6.
5. Benussi S, Pappone C, Nascimbene S, Oreto G, Caldarola A, Stefano PL, et al. A simple way to treat chronic atrial fibrillation during mitral valve surgery: the epicardial radiofrequency approach. Eur J Cardiothorac Surg. 2000;17:524-9.

6. Fuster V, Rydén LE, Cannom DS, Crijns HJ, Curtis AB, Ellenbogen KA, et al. ACC/AHA/ESC 2006 guidelines for the management of patients with atrial fibrillation: a report of the American College of Cardiology/American Heart Association Task Force on Practice Guidelines and the European Society of Cardiology Committee for Practice Guidelines (Writing Committee to Revise the 2001 Guidelines for the Management of Patients With Atrial Fibrillation): developed in collaboration with the European Heart Rhythm Association and the Heart Rhythm Society. Circulation. 2006;114:257-354.

7. Moe GK. On the multiple wavelet hypothesis of atrial fibrillation. Arch Int Pharmacodyn Ther. 1962;140:183-8.

8. Allessie M, Lammers WJEP, Bunke FI, Hollen J. Experimental evaluation of Moe's multiple wavelet hypothesis of atrial fibrillation. In: Zipes D, Jalife J, eds. Cardiac Electrophysiology and Arrhythmias. New York: Cruno and Straiton; 1985:265-75.

9. Wijffels MCEF, Kirchhof CJHJ, Doland R. Atrial fibrillation begets atrial fibrillation. Circulation. 1995;92:1954-68.

10. Haissaguerre M, Jais P, Shah DC, Takahashi A, Hocini M, Quiniou G, et al. Spontaneous initiation of atrial fibrillation by ectopic beats originating from the pulmonary veins. N Engl J Med. 1998;339:659-66.

11. Li D, Fareh S, Leung TK, Nattel S. Promotion of atrial fibrillation by heart failure in dogs. Atrial remodeling of a different sort. Circulation. 1999;100:87-95.

12. Goette A, Staack T, Röcken C, Arndt M, Geller JC, Huth C, et al. Increased expression of extracellular signal-regulated kinase and angiotensin-converting enzyme in human atria during atrial fibrillation. J Am Coll Cardiol. 2000;35: 1669-77.

13. Kawara T, Derksen R, de Groot JR, Coronel R, Tasseron S, Linnenbank AC, et al. Activation delay after premature stimulation in chronically diseased human myocardium relates to the architecture of interstitial fibrosis. Circulation. 2001;104: 3069-75.

14. Jahangiri M, Weir G, Mandal K, Savelieva I, Camm J. Current strategies in the management of atrial fibrillation. Ann Thorac Surg. 2006;82:357-64.

15. Bakir I, Casselmann FP, Brugada P, Geelen P, Wellens F, Degrieck I, et al. Current Strategies in the surgical treatment of atrial fibrillation: review of the literature and Onze Lieve Vrouw Clinic's strategy. Ann Thorac Surg. 2007;83:331-40.

16. Roy D, Talajic M, Dorian P, Connolly S, Eisenberg MJ, Green M, et al. Amiodarone to prevent recurrence of atrial fibrillation. N Engl J Med. 2000;342:913-20.

17. Khargi K, Laczkovics A, Haardt H, Lemke B, Müller KM, Mügge A, et al. Concomitant anti-arrhythmic procedures to treat permanent atrial fibrillation in CABG and AVR patients are as effective as in mitral valve patients. Read at the 3rd EACTS/ESTS Joint Meeting, September 15, 2004, Leipzig, Germany.

18. Geidel S, Ostermeyer J, Laß M, Geisler M, Kotetishvili N, Aslan H, et al. Permanent atrial fibrillation ablation surgery in $\mathrm{CABG}$ and aortic valve patients is at least as effective as in mitral valve disease. Thorac Cardiovasc Surg. 2006;54:91-5.

19. Gillinov AM, Pettersson G, Rice TW. Esophageal injury during radiofrequency ablation for atrial fibrillation. J Thorac Cardiovasc Surg. 2001;122:1239-40.

20. Melo J, Berglin E, Sie H, Benussi S, Knaut M, Williams M, et al. Surgery for atrial fibrillation in mitral patients with and without additional procedures. Results at 5 years from an international registry. Read at the 86th AATS Annual Meeting, May 1, 2006, Philadelphia, Pennsylvania.

21. Geidel S, Ostermeyer J, Lass M, Betzold M, Duong A, Jensen F, et al. Three years experience with monopolar and bipolar radiofrequency ablation surgery in patients with permanent atrial fibrillation. Eur J Cardiothorac Surg. 2005;27:243-9.

22. Beukema WP, Sie HT, Misier AR, Delnoy PP, Wellens HJ, Elvan A. Predictive factors of sustained sinus rhythm and recurrent atrial fibrillation after radiofrequency modified Maze procedure. Eur J Cardiothorac Surg. 2008;34:771-5.

23. Gaynor SL, Schuessler RB, Bailey MS, Ishii Y, Boineau JP, Gleva MJ, et al. Surgical treatment of atrial fibrillation: predictors of late recurrence. $J$ Thorac Cardiovasc Surg. 2005;129:104-11.

24. Ad N, Barnett S, Lefrak EA, Korach A, Pollak A, Gilon D, et al. Impact of followup on the success rate of the cryosurgical maze procedure in patients with rheumatic heart disease and enlarged atria. J Thorac Cardiovasc Surg. 2006; 131:1073-9.

25. Brignole M, Vardas P, Hoffman E, Huikuri H, Moya A, Ricci R, et al. Indications for the use of diagnostic implantable and external ECG loop recorders. Europace. 2009;11:671-87. 